\title{
EL INTENTO DE C.S. PEIRCE POR "PRESENTAR ANTE EL MUNDO" SU LÓGICA EN 1902
}

Charles S. Peirce, La lógica considerada como semiótica. El índice del pensamiento peirceano, introd., trad. y notas Sara Barrena, Biblioteca Nueva, Madrid (Clásicos del Pensamiento, 41), 2007, $162 \mathrm{pp}$.

RoBERTo NARVÁEZ Instituto Cultural Helénico gogmagog@prodigy.net.mx

\section{Introducción}

A principios del siglo XX, el millonario empresario Andrew Carnegie se retiró de los negocios para cultivar la filantropía. Desarrolló entonces varios proyectos exitosos, entre otros la fundación de la célebre Institución Carnegie (con sede en Washington). De 1902 a 1904, esta Institución destinó la mayor parte de su presupuesto a un fondo de becas para financiar las investigaciones de científicos en lo individual. Las bases de la convocatoria inaugural fueron leídas y meditadas cuidadosamente por Charles S. Peirce, el más original y fecundo entre los fundadores del pragmatismo estadounidense. Estimando que tenía lo necesario para satisfacer los requisitos y, por lo tanto, obtener el apoyo económico, Peirce firmó el 15 de julio de 1902 su carta de solicitud y los lineamientos de su plan de trabajo para someterlos a la evaluación del Comité Ejecutivo de la Carnegie. Si lo favorecían, gastaría el dinero y el tiempo cedidos en completar 36 "memorias" con los resultados que había obtenido tras dedicar casi cuatro décadas al estudio de la lógica pura y cuestiones lógicas relativas a la metodología de las ciencias exactas, naturales y de otras clases. Al final, sin embargo, el ganador de la beca fue alguien más.

La versión oficialmente recibida de la solicitud más un cúmulo de los borradores que Peirce presumiblemente redactó con vistas a establecer el texto final enviado, forman un manuscrito que Richard Robin identificó en su Annotated Catalogue of the Papers of Charles S. Peirce [Cátalogo anotado de los papeles de Charles S. Peirce] con la clave L75 (Robin 1967). El potencial informativo de este material sobre la versatilidad inquisitiva, el sistema de trabajo, 
la solidez intelectual y la vida de Peirce pasó en general inadvertido hasta que Joseph Ransdell, al promediar la década de 1980, se dio a la tarea de ponerlo a punto para su edición impresa. Emprendió una labor de reconstrucción a partir de la solicitud original y los borradores, y al cabo produjo un texto que denominó Versión 1 (siendo la Versión 2 el L75 según lo describe Robin en su catálogo). Por diversos motivos terminó publicando su Versión 1 en la internet, bautizándola como Logic, Considered as Semeiotic (Ransdell 1998b). Sara Barrena, uno de los miembros fundadores del Grupo de Estudios Peirceanos (GEP) de la Universidad de Navarra (al que contribuye regularmente con finas traducciones al castellano de la obra de Peirce), tuvo a su cargo la edición española de aquel volumen que tituló La lógica considerada como semiótica. El índice del pensamiento peirceano, y cuya reseña fijará las directrices del presente estudio crítico.

Para redactar la "Introducción" (dejando aparte las noticias biográficas) y las "Notas sobre el texto e indicaciones sobre la presente edición", Barrena se limitó a parafrasear lo dicho por Ransdell en secciones determinadas del ensayo "La significación de la solicitud de Peirce a la Institución Carnegie" (Ransdell 1998a), que constituye la "Introducción editorial" a las dos versiones en hipertexto del L75. Así, resulta lícito asumir que Barrena juzgó lo más oportuno reproducir el —por así llamarlo- modelo de interpretación filosófica-biográfica, de crítica textual y de metodología erudita del L75 que propuso Ransdell en el ensayo citado. Según este autor, para incursionar con provecho en La lógica considerada como semiótica (en adelante abreviado LS), es necesario dar por fundada la hipótesis de que tal escrito admite una interpretación como "representación tópica" del sistema filosófico entero de Peirce, y por tal motivo es permisible concebirlo y utilizarlo, fundamentalmente, como un "índice del pensamiento peirceano" en general, pero sobre todo para fines de investigación erudita y especializada. Ransdell adoptó esta hipótesis como una guía para tratar de explicar ciertos aspectos de la forma y los contenidos de LS. Ahora bien, es de creer que Barrena suscribe tal hipótesis, pues de otra manera se torna problemático entender su elección de la frase "El índice del pensamiento peirceano" como subtítulo para su edición.

En mi opinión, sólo en un sentido muy especial y limitado puede juzgarse válido calificar a LS de "índice", mas niego en definitiva que sea correcta la idea de tenerla por un "índice" en el sentido de que sirve para "representar tópicamente" el "sistema filosófico" íntegro de Peirce. Pienso que la postura final que asumió Ransdell 
en este caso dependió de una circunstancia fatal: su precipitación sistemática durante la lectura del manuscrito y la reflexión posterior en torno a su significado, sus alcances y su lugar dentro del corpus peirceano, exagerando por esa misma causa la importancia relativa de unas partes en detrimento de la de otras. El germen de semejante actitud brotó de su complacencia para dejarse llevar por ciertas preconcepciones acerca del modo en que sería más adecuado clasificar a Peirce como pensador y escritor. Sin embargo, Sara Barrena al parecer nunca consideró necesario indagar si en la configuración del modelo al que decidió ceñirse había problemas dignos de atención; tal debió ser, entonces, la precipitación cometida por su parte. Como haya sido, es tiempo de revisar las dos principales objeciones que, a mi juicio, se deben oponer a la visión de Ransdell (y, por implicación, de Barrena). Es lo que trataré de hacer, sucintamente, en la sección 1. Dedicaré la sección 2 a exponer y comentar el tipo de lectura crítica que considero más recomendable practicar si se desea obtener un amplio beneficio al tratar con La lógica considerada como semiótica. ${ }^{1}$

\section{Objeciones a las posturas críticas de Ransdell}

1.1 .

Comencemos por el argumento de que LS es un índice que "representa tópicamente" el "sistema filosófico" total peirceano. Después de reordenar todos los borradores disponibles y las versiones finales de las 36 memorias, Ransdell se interrogó sobre el posible significado del orden secuencial que acabaron presentando. Juzgó legítima la suposición de que el hecho revelaba una intención original de Peirce de "analizar" su proyecto "en términos del orden presuposicional de los tópicos" (Ransdell 1998a), entendiendo por "tópicos" cada uno de los temas a tratar en las respectivas memorias. A continuación infirió Ransdell que el afán último de Peirce fue cifrar en un conjunto unitario la clase precisa de interrelaciones mantenidas por todos los elementos constituyentes de su "sistema filosófico". Estimo muy improbable que tal haya sido el caso. Peirce nunca se planteó la meta de forjar y representar de cualquier manera un "sistema filosófico". $\mathrm{Su}$ tema fue siempre la lógica, y de manera prominente (sobre todo en épocas tardías) la lógica de los métodos aplicados por los investigadores en los más diferentes ámbitos de las ciencias — destaca la

${ }^{1}$ Nota sobre las referencias a los Collected Papers de Charles S. Peirce: al citar su procedencia entre paréntesis, incluiré junto a los demás datos las siglas $C P$ y el número del volumen, al estilo convenido por la mayoría de los eruditos peirceanos. 
"ciencia histórica"-, comenzando por el análisis de sus respectivos propósitos. ${ }^{2}$ Así, no debe sorprender que el objetivo de Peirce al planear LS haya sido exponer sus resultados en la investigación de la lógica concebida en los términos recién apuntados, como él mismo lo enunció (Peirce 2007, pp. 30, 33). Estos resultados derivaban del método científico; la mayoría fue transmitida en artículos, conferencias y otros medios desde 1856, pero de un modo tan fragmentario que se precisaba ordenarlos en "un sistema unitario" y bajo un control tal de la lógica que ninguna de las partes pudiese revisarse por separado "de una forma que le haga justicia, ya sea respecto a su significado o respecto a sus evidencias" (Peirce 2007, p. 30). En definitiva, Peirce tenía el anhelo de estructurar y poner por escrito un sistema, sí, pero uno de lógica y no de filosofía. ${ }^{3}$ La opinión divergente de Ransdell en torno a este punto surgió, principalmente, de un incisivo deseo de vindicar a Peirce como un "filósofo sistemático" en contra de quienes, juzgando por la ausencia de tratados entre sus obras editadas y por la dispersión, el desarreglo y, muchas veces, lo incompleto de sus papeles póstumos, tienden a encasillarlo entre los pensadores "asistemáticos". Muchos eruditos peirceanos comparten esta postura, mas ninguno ha propuesto argumentos $\mathrm{u}$ ofrecido hipótesis verdaderamente rigurosas de que el corpus peirceano, tal y como se presenta ante nuestra vista, reúne características propias de un "sistema filosófico". Desde luego, tienen razón cuando señalan que calificar de asistemática una obra por su apariencia desordenada o truncada, cuando tal dictamen surge tan sólo de presumir que es una especie de regla general el extrañar la sistematicidad en todo legado filosófico privado de una edición caracterizada por ciertos rasgos formales, constituye un despropósito. Una investigación empírica bien diseñada de corpus filosóficos varios, y no sólo el peirceano, devolvería importantes elementos de juicio para sostener la tesis de que una generalización similar es inaceptable. $\mathrm{Y}$ esto es, de hecho, lo que a propósito de Peirce contribuyó a probar el esfuerzo de

${ }^{2}$ Cfr. Fisch 1986, pp. 314-315.

${ }^{3}$ Es importante no confundir la noción que tenía Peirce de una "arquitectónica filosófica" con la noción tradicional de sistema filosófico, esto es, la configuración más acabada, rigurosamente articulada y ordenada que asume el pensamiento de un filósofo tras años de ejercicio intelectual. El concepto de "arquitectónico" en Peirce se refiere a la aprehensión de concepciones científicas para incorporarlas a una teoría filosófica, en la cual se determina metódicamente la función de cada concepción incorporada, según trató de asentarlo en su escrito "La arquitectura de las teorías" de 1891. En el núcleo de esta noción domina su doctrina del realismo evolutivo, caracterizada por su oposición a las visiones del realismo y el idealismo que llegó a conocer con mayor profundidad. Cfr. Hausman 1993, p. 119. 
reconstrucción de Ransdell. En definitiva, Peirce ocupó su vida en erigir un sistema, pero se trató, repito, de un sistema de lógica; así lo enunció él mismo y así lo revelará cualquier análisis inmanente y comparativo de LS y otros textos suyos, siempre que se ejecute con cautela y sin preconcepciones. ${ }^{4}$

\section{2 .}

La segunda objeción se dirige a la interpretación de que LS, tomada como una obra autónoma, representa una especie de "índice de materias" para orientarse al explorar las obras de nuestro autor, particularmente con fines editoriales. Asevera Ransdell (1998a) que esa supuesta propiedad determina su auténtica "significación" dentro del corpus peirceano. Para derivar esta inferencia Ransdell incurrió con especial ahínco en la misma falla que lo encaminó por la ruta del equívoco durante todo su procedimiento de crítica textual: ejercitar sistemáticamente una lectura precipitada, o peor aún, incompleta - en el sentido de que fue selectiva, pero conforme a un mal arbitrio, por así decir - de LS. En efecto, la revisión vigilante de su "Introducción editorial" muestra que para él este manuscrito se compone solamente de la sección 1 con su "Anexo" —esto es, la exposición sumaria de los contenidos de las 36 memorias - y la Memoria 1 "Sobre la clasificación de las ciencias teoréticas de investigación". ¿Por qué dejaría fuera las 35 memorias y las 8 secciones restantes? Trataré de explicar este singular gesto.

En la sección 1, Ransdell creyó localizar toda la información necesaria para inferir que Peirce deseaba exponer un "sistema filosófico"

\footnotetext{
${ }^{4}$ Véase, por ejemplo, la siguiente afirmación extraída del artículo "Lo que es el pragmatismo" (1905): "Baste decir [...] que el pragmatismo no es en sí mismo una doctrina de metafísica, ni tampoco un intento de determinar la verdad de las cosas, sino sólo un método para averiguar los significados de las palabras brutas y de los conceptos abstractos [...]. En cuanto a los efectos posteriores e indirectos de practicar el método pragmatista, esa es otra cuestión bastante diferente" (Peirce 2008, p. 65; este texto, por cierto, ha sido traducido también por Sara Barrena). Admitiré que uno de esos "efectos posteriores e indirectos" podría ser, justamente, forjar todo un sistema filosófico, incluso así lo sugiere, o podría pensarse acaso que lo sugiere, el siguiente fragmento (1904): "La palabra pragmatismo fue inventada para expresar una cierta máxima de lógica, la cual [...] envuelve todo un sistema de filosofía"; pero no asirse de pronto a la literalidad de esta última frase, leer primero la inmediatamente subsecuente: "La máxima pretende suministrar un método para el análisis de conceptos" (CP 8: 191). Más adelante comentaré sobre la importancia de atender con cuidado los desarrollos prácticos de esta máxima, conforme a las declaraciones de Peirce, a fin de comprender con mejor conocimiento de causa el sitio que le asignó a la Lógica en su (tardía) clasificación de las ciencias.
} 
- lo cual es discutible, como vimos en el punto anterior- .5 Pero evidentemente no supo, o no quiso, anticipar ninguna objeción de posible interés a su conclusión, luego se afincó en ella. Posteriormente, cuando recorrió el "Anexo" le pareció natural deducir que los títulos o encabezados de cada memoria representan algo así como los descriptores básicos para identificar, distinguir e interrelacionar analíticamente cada una de las divisiones del "sistema" peirceano, dicho en otros términos, que funcionan como las entradas en un "índice de materias". Tenemos aquí la causa del sesgo fatal que vuelve inaceptable su interpretación: en lugar de observar críticamente, con calma y sin prejuicios, el contenido de cada memoria, Ransdell exageró la lectura de los encabezados al percibir que todos pueden ocupar un sitio debajo de alguna de las divisiones de la Ciencia teórica en la clasificación de las ciencias incorporada a la Memoria 1 (Peirce 2007, pp. 41-42). Dicha clasificación pretende ser natural, estar gobernada por una interdependencia de principios y basar su ordenamiento en términos de una presuposición jerárquica de los objetos, regulada por la función de las tres categorías de la experiencia (cualidad, reacción y mediación, o primeridad, segundidad y terceridad) entre todas las actividades de investigación ahí clasificadas, de acuerdo con el modo en que Peirce abordó normalmente esta cuestión desde 1902 — cuando más tarde - hasta su muerte (Kent 1987, pp. 121-124). De este modo, la ciencia práctica (o artes), por ejemplo, presupone que la ciencia teórica está entre las variedades científicas; las ciencias de revisión (o filosofía sintética) presuponen que las ciencias de investigación están entre las especies científicas; la filosofía o Cenoscopia ${ }^{6}$ presupone que las matemáticas están entre los géneros, y las ciencias normativas presuponen que las categorías están entre las familias. Así, cuando Ransdell vio que los encabezados de las memorias 2 a 4 aluden a temas de matemáticas, juzgó apropiado colocarlos bajo el género "Matemáticas" en el esquema peirceano, pues dio por sentado que justo para potenciar, en algún individuo del futuro, una

\footnotetext{
${ }^{5}$ Posiblemente Sara Barrena no acordaba completamente con Ransdell sobre esto, juzgando por lo que dice en su "Introducción" a LS: "[en] las 36 memorias Peirce elabora una especie de índice de lo que sería su sistema lógico [...]" (en Peirce 2007, p. 18; cursivas mías). Sin embargo, deja sin explicar por qué dicho sistema sería precisamente lógico y no de otra clase, además, el calificarlo de índice, aún si lo hace por aproximación, digamos, no es del todo acertado. Tal y como aparece, pues, el fragmento citado sería interpretable como una mera desviación incidental respecto al modelo crítico filosófico-biográfico de Ransdell.

${ }^{6}$ Referente a la philosophia prima o tipo de conocimiento que se basa en la experiencia universal. Peirce tomó el vocablo de Bentham (Peirce 2007, p. 42).
} 
decisión semejante, Peirce mismo distribuyó temáticamente las memorias como lo hizo; de idéntica manera pensó Ransdell sobre las memorias 5 a 8: ya que se refieren a las categorías, procede agregarlas a la familia "Fenomenología" (o "Faneroscopia", como también la denominaba Peirce). Siguió en el mismo estilo con las 28 restantes.

En relación con este asunto, Ransdell, en principio, actuó razonablemente, pues no hay duda de que Peirce basó la organización de LS en su clasificación de las ciencias. Pero fue sólo una parte de dicha clasificación la que le sirvió de base. Ésta es una observación capital; nótese, en efecto, que cuando se termina de distribuir los 36 encabezados como hizo Ransdell, los tres últimos acaban bajo la familia "Metafísica". Sin embargo, el esquema de Peirce no culmina en la metafísica, ni siquiera es con ella que la clasificación de las ciencias de investigación toca su fin. Como se puede comprobar (Peirce 2007, p. 41), al género de la Cenoscopia sigue el de la Idioscopia o ciencia especial, y a éste otras especies, familias, órdenes, clases, etcétera. Si Ransdell estuviera completamente en lo correcto al suponer que Peirce le facilitó por adelantado, digamos, el sistema reconstructivo para el LS mediante la clasificación que introdujo en ese mismo texto, se impone la urgencia de explicar la causa de que Peirce no preparase las memorias que corresponderían "temáticamente" a los rubros restantes en la clasificación. Esta consideración importa para discutir el argumento de que Peirce articuló las diferentes partes de su "sistema filosófico" según su esquema clasificatorio (véase Ransdell 1998a), y por ello situó la memoria "Sobre la clasificación de las ciencias teoréticas de investigación" en el número 1 . Y lo primero y último en reclamar la crítica es aquella suposición ransdelliana de que los propósitos y métodos que guiaban, o por lo menos alguna vez guiaron, a Peirce en sus ensayos clasificatorios de las ciencias fueron los mismos que habría usado para proyectar LS conforme al deseo de dar un "panorama" de su "sistema" — no formado deductivamente por la operación de axiomas y teoremas, a lo Spinoza o Descartes, sino "basado en las relaciones de presuposición y los principios estructurantes ubicuos generados implícitamente por la aplicación recursiva de su teoría de las categorías" (Ransdell 1998a)—. En este caso, el escollo fatal en el método interpretativo y crítico de Ransdell no depende ya tanto de las preconcepciones originadas por su hambre de vindicar el "sistematismo" de Peirce, como de una mala comprensión elemental de lo que este pensador buscaba al clasificar las ciencias.

Sobre esta cuestión es justo conceder a Ransdell el beneficio de la duda, por lo menos hasta cierto punto, ya que para comprender 
la singular actitud taxonómica vitalista, evolucionista y "sinequista"7 con la que Peirce estableció un sentido específico de clase natural para diseñar el método apropiado de jerarquizar los diferentes intentos humanos por averiguar la verdad (es esto lo que entendía por "ciencias"), primero hace falta examinar profundamente la clave última de metodéutica en que moldeó progresivamente sus teorías de la cognición, los signos y las probabilidades; las relaciones de precedencia entre lógica, ética y estética, y —muy especialmentelos orígenes, el crecimiento y el significado (de tipo didáctico, sobre todo) de la historia de las ciencias. ${ }^{8}$ Subrayo, entonces, que sólo un desplante de arrogancia podría forzarme a promover la condena de Ransdell como un mal intérprete de la clasificación peirceana de las ciencias; no obstante, insisto en que su elemental acercamiento a la cuestión, juzgándola exclusivamente por cuanto afectó su tratamiento de $L S$, resultó fallido por haberlo conducido según la falsa suposición de que Peirce clasificaba las ciencias con el propósito, o al menos un propósito entre varios, de que eventualmente esas clasificaciones funcionarían como un índice de su "sistema filosófico", o dicho burdamente, que en algún futuro podrían servir a potenciales editores como una especie de "auxiliar organizativo autorizado". Más adelante trataré de mostrar que para la concepción y el proyecto de LS gobernó, como pensamiento nuclear, el de la metodéutica lógica entendida como instrumento para descubrir y entender la naturaleza del buen razonamiento científico, la razón de ser de ciencias y científicos y, por derivación analítica, el sentido y propósitos de una clasificación natural de las ciencias.

Es interesante reconocer y comentar el hecho de que, en la fidelidad a esta vía incorrecta de interpretación, Ransdell no ha estado solo. Entre sus predecesores destacan Knight W. McMahan, quien hacia 1941 preparó un catálogo mecanografiado de los manuscritos peirceanos en los archivos de la biblioteca Widener de Harvard, y el ya citado Richard S. Robin en 1967. Robin expresamente nos informa que se plegó a la estrategia criticada dentro de ciertos límites, atendiendo a "fines prácticos" exclusivamente; pero también desliza una nota insostenible: tal procedimiento es ventajoso, entre otras razones,

${ }^{7} \mathrm{O}$ "sinejista", como algunos traducen la voz synechism, continuidad, continuo.

${ }^{8}$ Se avanzará poco hacia la comprensión de este hecho mientras no se acometa un estudio realmente imaginativo, amplio y consecuente de las ideas de Peirce como investigador y crítico de la Historia y de los métodos de la investigación histórica (mediando una legítima comparación entre su postura y la de ciertos pensadores que lo precedieron, por ejemplo, William Whewell y Charles Babbage), en particular los aplicados a la historia de las ciencias y la tecnología. 
por cuanto implica utilizar "el esquema del propio Peirce $[\ldots]$ confeccionado para la ocasión" (Robin 1967). Esta cita manifiesta que Robin comparte con Ransdell la creencia de que alguna vez Peirce elaboró sus clasificaciones con el designio de producir un "índice por tópicos" o "de materias" de sus obras con la mira puesta en editores del porvenir. Así, las posturas de Ransdell, Robin y otras análogas deberían ponerse a discusión, o de plano impugnarse, por todas las razones expuestas.

Realmente no debería extrañar que cuando determinados eruditos peirceanos asumen funciones editoriales o de catalogación se dejen seducir por la identificación apresurada de las taxonomías científicas de Peirce con un "índice" de cierto tipo, pues ello les genera la ilusión de poseer, al fin, un medio ideal para agilizar la datación, glosa, edición, introducción y publicación de sus textos en una forma racional. Sería cuando menos muy severo culparlos por conducirse así, al enterarnos de que los manuscritos sobrevivientes de Peirce colman un acervo de casi 100 mil páginas autógrafas, mecanografiadas e impresas — notas, artículos, cartas, traducciones anotadas, planes de libros, gráficos lógicos, teoremas y pruebas matemáticas, etcétera- - Y no son de intelección inmediata, en absoluto, motivo por el cual todavía hoy sigue siendo prácticamente imposible darlos a las prensas de una manera que satisfaga plenamente las exigencias críticas de todos los interesados en tener acceso a ellos. Así ocurrió, por citar los dos ejemplos de mayor calibre, con los Collected Papers (8 volúmenes editados a intervalos entre 1931 y 1954), así ocurre y seguirá ocurriendo con cada nueva entrega de los Writings of Charles S. Peirce (6 de 30 tomos anticipados han visto ya la luz), indudablemente la empresa más ambiciosa que tiene en marcha el Peirce Edition Project (PEP) de la Universidad de Indiana en Bloomington. En vista de tal situación, a quienes nos ocupamos en la obra de Peirce nos resta confiar en la erudición calificada y las habilidades críticas de los editores en turno, comprendiendo su predisposición a echar mano de métodos o tácticas que faciliten su labor. Con todo, es preciso advertir que las cosas no marcharán por el mejor camino si el expediente seleccionado, así el proyecto esté limitado a la edición de una sola obra - como es el caso de LS-, se basa en interpretaciones abusivas, precipitadas, confusas, o de cualquier modo forzadas. Una cosa es buscar inspiración o sugerencias para trazar un método editorial adecuado en una clasificación que se toma como modelo ordenador, y otra decir, siguiendo a Ransdell, que ese modelo fue creado ex profeso para servir a editores futuros como la directriz ideal de sus empeños. Lo primero es muy pertinente y 
acaso resultará fructífero si se lo emplea bajo control, mas lo segundo es poco responsable intelectualmente, revela un entendimiento defectuoso de varios aspectos en los métodos de la crítica textual, y acaba por sembrar de riesgos innecesarios todo intento serio de comprender y utilizar adecuadamente la obra resultante.

\section{Hacia un modelo de crítica textual consecuente}

A continuación expondré las observaciones y reflexiones básicas que, según pienso, debería normalmente propiciar un estudio cauteloso de la distribución y secuencia de los textos reunidos en La lógica considerada como semiótica.

2.1 .

El dato esencial a recordar siempre es que se trata de un manuscrito concebido y redactado como una carta en solicitud de una beca. La Institución Carnegie publicó una convocatoria de 6 bases (el propio Peirce - 2007, p. 161 — alude a ellas en la sección 9) para concursar por esa beca. Y como lo mencioné en el primer párrafo de la introducción, Peirce meditó sobre dichas bases, sobre su espíritu, en una vena determinada. Las dotó al cabo de un cierto significado cuya valoración lo convenció de hallarse listo para concursar. Así surgió la, digamos, condición biográfica decisiva para que LS adquiriera unos rasgos formales específicos, y muy significativamente la división en secciones y el Anexo a la sección 1. El análisis atento de cada sección permite apreciar hasta qué punto era realmente intenso el anhelo peirceano de apoyo económico para realizar este proyecto, siendo meramente circunstancial, por cierto, el hecho de que la oportunidad de obtener el dinero se le presentase en 1902 (el año inmediatamente anterior había buscado lo mismo por otras vías, y con propósitos en gran medida idénticos). ${ }^{9}$ Esto lo demuestran las varias iniciativas

${ }^{9}$ En abril de 1901 Peirce escribió a Samuel Langley, el entonces secretario del Instituto Smithsoniano, para solicitarle la oportunidad de publicar en el Anuario de dicho Instituto sus teorías de lógica y de la naturaleza del razonamiento científico. El proyecto literario que describe no se compararía en extensión con lo que habría completado - tal vez - en caso de obtener la beca Carnegie el año siguiente, pero el plan de los contenidos es muy similar. A la postre, Langley no le encargó el texto planteado, sino otro a propósito de David Hume y la cuestión de los milagros (según la examina Hume en el capítulo $\mathrm{X}$ de An Inquiry Concerning Human Understanding). Peirce redactó por lo menos una versión que satisfizo parcialmente a Langley; de cualquier forma, el artículo — centrado en el análisis del testimonio humano desde la perspectiva probabilística, antes que en los asertos de Humenunca se publicó en el Anuario (Wiener 1958, pp. 274, 279). Peirce, dicho sea de 
que propuso al Comité Ejecutivo de la Carnegie para asegurar la realización del proyecto sin dispendios inútiles en tiempo y dinero. De hecho, las secciones 2 a 8 fueron planeadas casi exclusivamente como medios transmisores de tales iniciativas, como lo delatan sus títulos: "Estimación de la utilidad del trabajo" (2), "Estimación de otros gastos implicados" (4), "Plan sugerido para la ayuda solicitada" (6), y "Coste neto probable" (8), por citar sólo cuatro. En definitiva, pues, Peirce dedicó la sección 1 a describir su proyecto y las secciones restantes a estimar su factibilidad financiera. Y si fue así, entonces LS no se agota en el Anexo a la Memoria 1, como al parecer lo piensa Ransdell. Para comprender a fondo su significado como obra autónoma es obligatorio reconocer esto.

\section{2 .}

Ransdell ha declarado que la carta-solicitud oficialmente recibida estaba incompleta y mal estructurada (Ransdell 1998a). Pero nunca expone con claridad las razones de su aseveración; tampoco es convincente al afirmar que sólo en su reconstruida Versión 1 es posible leer ya el texto completo y bien estructurado (Ransdell 1998a). Lo único cierto es que las secciones 2 a 8 dejan patente la conciencia de Peirce - y el grado de su ansiedad retórica por conseguir exteriorizarla- con respecto a lo que deseaba y necesitaba. Parece, pues, improbable que hubiera remitido a la Carnegie un material desaliñado en cualquier sentido. No obstante, quizá Ransdell habla de "mala estructura" para referirse a las dificultades de lectura impuestas por ciertos modos de redacción. Si éste fue el caso, acertó, ya que Peirce normalmente sufría para redondear sus periodos y, por lo tanto, finiquitar cuantos escritos iniciaba, un hecho bien conocido por los especialistas en su obra. El mismo Peirce notifica de esto a sus jueces en la sección 1, al promediar una relación biográfica (Peirce 2007, pp. 32, 35). Se trata de un dato muy pertinente de considerar si deseamos comprender el impacto de su constitución psíquica como un factor determinante en la configuración de su pensamiento, su estilo y sus métodos de trabajo. ${ }^{10}$

paso, reservaba la Memoria 22 de LS para insertar ese artículo (Peirce 2007, p. 113), acusando de tal modo su satisfacción con el método de examinar testimonios y evidencias históricas ahí expuesto, pero también, y de manera más interesante, la firmeza de su decisión de "presentar ante el mundo su lógica".

${ }^{10}$ Tengo entendido que así lo ha hecho Shea Zellweger, autor también de una reconstrucción del L75. Zellweger, psicólogo académico, estudió el método compositivo empleado por Peirce en el plan para LS, confiando en que ello revelaría datos importantes sobre la psicología de la investigación (Ransdell 1998b). La versión de 
2.3 .

En LS, Peirce buscaba conjuntar cuanto de importancia se localizara en sus artículos y otros textos publicados desde 1857, por lo menos, y organizarlo de modo que ninguna parte meritoria luciera "separadamente de una forma que le haga justicia, ya sea con respecto a su significado o [...] a sus evidencias" (Peirce 2007, p. 30). La idea central era distinguir y explicitar las teorías de los tipos de razonamiento que se aplican en las ciencias y los que se aplican en la vida cotidiana. El principal motivo de la distinción surge de observar la función relativa del "instinto natural" en cada uno de dichos tipos de razonamiento. Por aquel instinto entiende Peirce una "disposición del alma" o "constitución" propia del individuo que le permite hallar una solución acertada a los problemas más a menudo que una solución errónea. Semejante instinto, al ser natural, deberá incidir tanto en el razonamiento práctico como en el que se forma y despliega en un laboratorio de química, por ejemplo. Y para fines de la distinción teórica buscada, el objetivo es determinar las razones de que tal incidencia deba limitarse en cada caso. Ese límite, nos dice Peirce, debe marcarse para el razonamiento científico, único que se aprende y controla, por especificación, de acuerdo con una finalidad ética. Descubrir la teoría de este razonamiento nos enseña cómo se debe razonar para trascender la logica utens de la vida diaria hasta llegar a la logica docens del científico. Como señaló acertadamente Max Fisch, Peirce se convirtió en un historiador de las ciencias para fomentar avances en la lógica científica (Fisch 1986, p. 238). Efectivamente, muchas evidencias nos obligan a pensar que la meta última de Peirce al estudiar y cultivar la lógica científica, crítica y objetiva, en coordinación con el escrutinio de la historia de las ciencias, era definir un arte de razonar con cuyo auxilio pudiera establecerse el "método de los métodos".

Ahora bien, el papel de la metodéutica es crucial en este proceso. Como dije anteriormente, resaltar la importancia de la metodéutica en la investigación de la lógica y de los métodos lógicos aplicados por los científicos (pero también, desde luego, por los propios lógicos) representaba uno de los dos anhelos máximos de Peirce al concebir

Zellweger no se ha publicado y es difícil obtenerla, mas el profesor André De Tienne, director del Peirce Edition Project (PEP), me ha comunicado por correo electrónico que actualmente se prepara una edición impresa y electrónica del L75, para la cual se consideran las reconstrucciones de Ransdell y Zellweger. 
LS. ${ }^{11}$ De hecho, por la reflexión consecuente de la metodéutica de la lógica discernió las dos "líneas de pensamiento" presentadas en la sección 2 con el propósito de influir en sus jueces para "estimar la utilidad del trabajo propuesto". La primera línea "tiene que ver con el valor de mis investigaciones consideradas como contribuciones a la ciencia pura; la otra está relacionada con su probable influencia, directa o indirecta, en el progreso de otras ciencias" (Peirce 2007, p. 149). Al hablar de "ciencia pura" Peirce se refiere a la "Lógica general", cuyo estado le parecía deplorable a la sazón (Peirce 2007, p. 150). En cuanto al "progreso de otras ciencias" (esto es, ciencias diferentes de la Lógica), veamos lo que puntualiza sobre la función de la metodéutica:

No soy de la opinión de que una ciencia de la lógica sea del todo indispensable para cualquier otra ciencia, porque todo hombre tiene su logica utens instintiva, que corrige gradualmente bajo la influencia de la experiencia. [...] el instinto, dentro de su propio dominio, está generalmente menos sujeto a error y es capaz de más sutileza que cualquier teoría humana $[\ldots]$. Hay muchos campos en los que pocos mantendrían que algún modo teórico de alcanzar conclusiones podría alguna vez ser tan seguro como el razonamiento instintivo natural $[\ldots]$. Sin embargo, si dejamos que el instinto pise más allá de sus propios límites [...] llega a ser la cosa más inútil del mundo, un verdadero pez fuera del agua. Las ciencias se equivocan a menudo: eso no puede negarse. Su historia contiene muchos antecedentes de tiempo y energía desperdiciados que una buena metodéutica podría haber evitado [...]. ¿Es el razonamiento el único asunto cuyo método no debería ser científica y minuciosamente analizado? (Peirce 2007, p. 149)

Aplicar una lógica minuciosa propende a mostrar el despropósito de cimentar la teoría de la lógica sobre la psicología, lo cual, según Peirce, equivale a dar por sentado que la lógica (la lógica crítica, o logica docens, en especial) es una mera cuestión de sentimiento o de gusto intelectual. La suposición correcta debería ser que el gobierno de la Lógica corresponde a la razón y al pensamiento. A este propósito definió alguna vez "Lógica" como la ciencia de la verdad y la falsedad, en tanto verdad y falsedad son propiedades exclusivas de las proposiciones; pero se trataría de proposiciones ubicadas en la mente, por lo que su ser conscientes o inconscientes no afecta

${ }^{11}$ Peirce deseaba subrayar el carácter normativo de la investigación metodéutica en general, de ningún modo suponía que con su guía la verdad se alcanza infaliblemente. Cfr. Anderson 1995, p. 50. 
sus valores de verdad o falsedad. Al cabo consideró más apropiado tratar la lógica como una teoría del razonamiento, provisto que sólo una mente puede ejecutar el razonamiento. Pero esto no implicaba que los fenómenos descritos por la psicología tuvieran alguna función de premisa en el desarrollo de aquella teoría. Este rechazo a ultranza del psicologismo en lógica (lo que solía entender, sin ulteriores matices, como el típico modo alemán - léase sentimentalista - de ver las cuestiones lógicas generales, véase Peirce 2007, pp. 78-79) lo mantuvo desde temprano en su carrera, y jamás lo abandonó. Sin embargo, no negaba que el razonamiento, en tanto podía incluirse en el estudio de la lógica, representara un proceso psíquico; esto no significaba que dicho estudio deba ocuparse de procesos psicológicos, que son irrelevantes para el propósito de la lógica (Peirce 2007 , p. 80); su objetivo, en rigor, debía ser indicar si las condiciones de un razonamiento son buenas o malas, hasta qué grado y para qué aplicaciones. La importancia última de aprender a discernir los razonamientos buenos de los malos yace en que por tal medio se obtiene una guía conductual segura, un principio regulador de simiente ética con cuyo auxilio controlamos el pensamiento (Peirce 2007, pp. 87-90). Mas debe comprenderse que Peirce, aquí, entiende la conducta como algo estrictamente relacionado con la actitud del experimentalista, mostrando en este modo preciso su apego a la versión elemental del pragmatismo que él fundó y defendió durante toda su vida. A partir de 1878 definió el pragmatismo, en lo general, como un método para determinar el significado de los conceptos intelectuales, aquellos en los que puede trabajar el razonamiento; la "máxima pragmatista" ordena que al aplicar ciertas clases de volición se obtendrán ciertas "percepciones compulsivas", esto es, líneas de conducta que ocasionan ciertas experiencias inevitables, todo lo cual descansa en consideraciones prácticas (CP 5: 8-9). En el artículo de 1905 "Lo que es el pragmatismo" Peirce definió "proposición" en un sentido preciso: aquello que se relaciona con cualquier aserción, mental y autodirigida o expresada hacia el exterior, justo como cualquier posibilidad se relaciona con su actualización (CP 5: 424, n. 1). Siempre que un hombre actúa con propósito lo hace bajo la creencia en algún fenómeno experimental; el significado racional de su acción consiste en ese fenómeno experimental - es decir, algo que seguramente, si cumple determinadas condiciones, ocurrirá a cualquiera en el futuro vivo- y no en el experimento (CP 5: 425427). El contenido intelectual de los símbolos no consiste en nuestra conducta, sino en nuestro concepto de lo que sería nuestra conducta en ocasiones concebibles ( $c f r$. CP 8: 208; véase Misak 2004, p. 11). 
En relación con esto se precisa distinguir las funciones relativas del concepto, entendido como lo que posee el modo de ser de un tipo general que es, o puede llegar a ser, la parte racional del contenido de una palabra (postura derivada de su adhesión al realismo escolástico extremo), y del método que prescribe la máxima pragmatista: rastrear en la imaginación las consecuencias prácticas concebibles, esto es, las consecuencias de la conducta deliberada, autocontrolada, de la afirmación o negación del concepto en turno; en suma, el contenido total de la palabra yace en su propio contenido intelectual, convenida la premisa fundamental de que todo pensamiento es de la naturaleza de un signo (CP 8: 191). ${ }^{12}$ Según esto, la prueba de que el pragmatismo es una doctrina correcta se obtiene mediante el análisis de los argumentos partiendo de una diferenciación entre tres tipos de razonamiento: deducción, abducción e inducción, y las razones de su exitosa injerencia en el desarrollo histórico de la ciencia moderna, en tanto que su aplicación faculta la extracción del contenido intelectual de cualquier símbolo (CP 8: 209). ${ }^{13}$

En resumen, el presupuesto fundamental de la investigación científica es la conformación de una acción a su ideal. Teóricamente la ética, primera división de las ciencias normativas según el esquema peirceano, proporciona esa conformación. La Lógica, tercera división de las ciencias normativas, presupone a la Ética, y ésta a la Estética, pues "no podemos saber cómo estamos deliberadamente preparados para pretender actuar hasta que no sepamos qué admiramos deliberadamente" (Peirce 2007, p. 58). Veamos la relación de esto con la concepción peirceana del pensamiento en su teoría de la verdad. Si el pensamiento es de la naturaleza de un signo (Peirce 2007, pp. 74-80), averiguar su método de operación nos enseña cómo se transforman los signos, por tanto, cómo se piensa; de este modo, la verdad será

${ }^{12}$ Peirce, influido por Kant, dio el nombre de "pragmatismo" y no "practicalismo" a su teoría lógica original por estimar que el primer término era más apto para designar una conexión inseparable entre la cognición racional y el propósito racional (CP 5: 412).

${ }^{13}$ Aceptar esta prueba permite establecer la verdad de la doctrina del sinequismo o sinejismo, es decir del continuo, propuesta por nuestro filósofo para explicar la existencia de posibilidades concretas y desarrolladas en el universo, a través de argumentos matemáticos y especulaciones no siempre inteligibles. En una relación estricta con los procesos de investigación, la idea del continuo tiende a resaltar la utilidad específica del método pragmático: simplificar los problemas cuando el propósito es no tanto saber la verdad como lograr un estado de creencia inmune a la duda (CP 5: 416). Según Peirce, el pensamiento del continuo es una "actividad lógica apropiada" para el intelecto y el sentimiento por igual, en tanto cada humano, en su propia naturaleza real, es un continuo (Peirce 1992, p. 163). 
el resultado último devuelto por la aplicación de este método. He aquí uno de los componentes cruciales del "pragmaticismo" (etiqueta con la que Peirce, tardíamente, buscó inmunizar su doctrina lógica contra los giros de varios "pragmatismos" crecientemente populares - representados por William James, F.C.S. Schiller, Josiah Royce y otros autores - cuya sustancia lógica desestimaba) radicalmente caracterizado como un método para aclarar el contenido intelectual de las proposiciones.

2.4 .

Peirce configuró el sentido y determinó el sitio de la metodéutica, o "retórica filosófica", en la clasificación de las ciencias normativas como una de las tres divisiones de la lógica, bajo el rubro de la filosofía o Cenoscopia (Peirce 2007, p. 41). Le asignó una función regulativa para interpretar la historia de las ciencias y criticar la metodología científica general. En relación con esto, es significativo leer en la Memoria 1 el primero de sus tres motivos fundamentales para ensayar una clasificación de las ciencias: "mirando menos a lo que ha sido el curso de la historia científica y más a lo que hubiera sido si se hubieran seguido los métodos teóricamente mejores" (Peirce 2007, p. 39). Para representarse con claridad todas las posibles ventajas que conllevaría el asentir a ese motivo, Peirce debió gastar años modificando su definición de Lógica a la luz de sus reflexiones en torno a la tríada de categorías que publicó en 1867, bajo el título "Sobre una nueva lista de categorías". El aprendizaje crítico y metodológico que le deparó aquella reflexión determinó la razón principal que lo hizo sentirse maduro para "presentar ante el mundo" sus resultados en lógica, tal y como lo declara a sus jueces (Peirce 2007, p. 30). Hacia 1902, pues, Peirce había sustituido ya la vieja definición de lógica como ciencia de las leyes formales de la relación de los símbolos con sus objetos por la del completo estudio cenoscópico de los símbolos, y en general de toda clase de signos, ya fueran éstos reales, imaginarios o tan sólo posibles, luego de madurar sus consideraciones sobre la naturaleza de los límites entre las ramas de la ciencia.

2.5 .

Sobre estas bases, en fin, acabó por concretarse el objetivo cabal de LS: tratar la Lógica como una semiótica formal y según su función entre las ciencias normativas, a las cuales considera "el polo opuesto de la esfera de la ciencia" por su "dualismo peculiar (que aparece en las distinciones de lo bello y lo feo, bien y mal, verdad y falsedad), 
[...] una causa de que se las confunda con las artes, [...] debido a que están en el borde entre las matemáticas y la ciencia positiva" (Peirce 2007, p. 57). Su gran abstracción, en principio, las vuelve aplicables a numerosas cuestiones — de aquí su confusión con las artes (Peirce 2007, p. 58) - y representan un problema cuya solución podría iluminar la naturaleza y función lógicas del pensamiento y, por extensión, del razonamiento en sus variedades práctica (logica utens) y científica (logica docens).

2.6 .

Lo expuesto en los apartados $2.3,2.4$ y 2.5 contribuye a explicar varias cosas sobre la estructura y organización de LS. En primer lugar, la función genuina, y por cierto crucial, de la Memoria 1: precisar el sitio de la lógica en la familia de las ciencias normativas. ${ }^{14}$ En segundo lugar, el hecho de que las memorias, aun si consideramos exclusivamente sus encabezados, refieran como sus "tópicos" (en el vocabulario de Ransdell) sólo los que van de las matemáticas a la metodéutica - parte de la Cenoscopia - en la lista de ciencias clasificadas. (Esta observación debería bastar para dar el golpe de gracia a la creencia de que dicha clasificación fue originalmente trazada para funcionar como el "índice" de un "sistema filosófico".) Los contenidos totales, y no solamente los títulos o encabezados, revelan que la temática gira en torno a la lógica considerada como semiótica formal y según su función entre las ciencias normativas, pero bajo el entendido de que esta perspectiva doble surgió de las constantes revisiones y modificaciones de Peirce a su tríada de categorías, su teoría general de los signos, su forma de ver las relaciones de presuposición entre lógica, ética y estética (Kent 1987, pp. 151-152) y la justificación para declarar que éstas, a su vez y en conjunto, presuponen las Matemáticas, ámbito en donde "los razonamientos [...] puros son perfectamente evidentes y no tienen necesidad de ninguna teoría de la lógica separada para reforzarlos", lo que significa que las matemáticas "son su propia lógica" (Peirce 2007, p. 38; véase Kent

${ }^{14}$ Esto se puede advertir leyendo detenidamente los textos que dedicó a la clasificación a partir de 1900, justo como lo hizo Beverly Kent en su brillante monografía (1987, pp. 112-117 en especial). En mi opinión, se requiere partir de una similar perspectiva comprensiva, analítica y de comparación intertextual para obtener una visión más clara de los métodos y, sobre todo, los propósitos de Peirce al clasificar las ciencias, antes de argumentar sobre la posible utilidad modélica de dicha clasificación para nutrir los avances en otros campos de investigación, por ejemplo, el del estatus actual de la interdisciplina, la transdisciplina y nociones relacionadas (como lo han hecho, por ejemplo, Pietarinen 2006 y Nubiola 2005). 
1987, pp. 72-73, 132). Las ciencias normativas, en cambio, deben apelar a la metodéutica, supuesto que "la teoría de cómo uno debería razonar depende de la propia finalidad última y se modifica con cada modificación de la ética" (Peirce 2007, p. 38). Se sigue que una ciencia de la lógica desarrollada como metodéutica, caracterizada por su no necesidad en el estudio de razonamientos matemáticos puros, tendrá una utilidad limitada a "la metafísica y las ciencias teoréticas especiales del lado físico y psíquico" (p. 38).

En tercer lugar, el hecho de que Peirce viera la necesidad de exponer todo esto en orden de presuposición, conforme a la jerarquía de las ciencias, explica la sucesión de las memorias por sus respectivos contenidos. A veces el asunto era tan complejo que su tratamiento debía fraccionarse en múltiples memorias. Al cabo, la distribución total se resolvió en cinco grupos mayores:

I) Memorias 2 a 4. Tratan sobre matemáticas (las de mayor simplicidad, sus concepciones, sus métodos de demostración).

II) Memorias 5 a 8. Sobre las categorías (sus cualidades, componiendo una tríada, en sus aspectos reactivos y mediatos, etcétera).

III) Memorias 9 a 28. En la 9 Peirce aclararía la relación de dependencia de la Lógica respecto de la Estética y la Ética, como preámbulo a su escrutinio minucioso como Lógica general y como semiótica formal y metodéutica. Las memorias 10 a 27 contendrían el análisis progresivo de la Lógica en esta secuencia: presuposiciones; sus relaciones con las psicología (tratando la "concepción lógica" de la mente, por ejemplo); definición (como semiótica formal; además, Peirce intentaría en este lugar deducir matemáticamente los principios de la lógica, operando con una definición de signo cifrada en la vinculación de una lógica de relaciones triádicas y una definición específica de "formal"); división (estequiología, crítica o "gramática especulativa", y metodéutica); los métodos para descubrir y establecer sus verdades (donde criticaría especialmente el estado de la Lógica general en su época); términos, proposiciones y argumentos; de la lógica crítica en general; sobre las primeras premisas (una discusión de los "juicios perceptivos" como punto central del argumento favorable a la idea de que ni la sensación ni la percepción constituyen primeras premisas); probabilidades (pretendía tratar demasiados asuntos relativos a esta teoría, para explicitar al final su inclinación a la doctrina de propensiones); la justificación de la abducción (explicaría cómo y por qué las categorías brindan esa justificación, y subrayaría el valor de la abducción como único tipo de inferencia que inicia una hipótesis 
científica) y, por último, la metodéutica, procurando asentar una concepción precisa de su naturaleza sobre la base de que, conforme a su aplicación,

los signos considerados se ajustarán a las condiciones de la crítica, y serán verdaderos. Pero así como la lógica crítica se pregunta si un signo corresponde a su objeto último pretendido, la realidad, y cómo, así la metodéutica mira al interpretante último que se persigue y se pregunta a qué condiciones debe ajustarse un signo para ser pertinente para su fin. (Peirce 2007, p. 124)

Ahora bien, la metodéutica "tiene un interés especial en la abducción" por cuanto su función es radicalmente económica (Peirce 2007, p. 124), pues dicta los procedimientos para elegir, de entre todas las hipótesis disparadas por la abducción, la merecedora de un tratamiento inicial (con el fin principal de rechazarla). El desarrollo de este fenómeno se contiene en la memoria 28, titulada justamente "Sobre la economía de la investigación".

IV) Memorias 29 a 33. Representan un intento de instaurar los sistemas de categorías que gobiernan el curso de la investigación, la sucesión de los sistemas de doctrina, las clasificaciones, y las formas de definir y clarificar las ideas. El propósito era formular progresivamente un "método general" y "métodos especiales tan generalizados como sea posible" (Peirce 2007, p. 132) que servirían para deducir la fórmula de la clasificación natural, la evolución, la historia del desarrollo intelectual y el curso (histórico) de la investigación. En opinión de Peirce, el estudio de las categorías controladoras de las fórmulas indicadas debería estar conectado con alguna ley capaz de exhibirse en la historia de las ciencias, y el descubrimiento de esa ley permitiría exhumar el secreto de las categorías de la jerarquía clasificatoria. "Ha sido - escribe - debido a una esperanza de que éste podría resultar ser el caso y de que esas categorías jerárquicas podrían tener otras aplicaciones útiles por lo que he invertido mucho estudio en la historia de la ciencia" (Peirce 2007, p. 132). La creencia suprema de Peirce, inspirada en gran medida por Comte, ${ }^{15}$ Whewell y Francis Bacon, entre otros pensadores, era que las ciencias progresan desde lo más abstracto hasta lo más concreto; tal es el hecho que debería exhibir como una ley toda ciencia (metodéuticamente) bien desarrollada (Peirce 2007, p. 133). Es manifiesto, así, que Peirce

\footnotetext{
${ }^{15}$ En torno a los momentos en que Peirce reconoció sus deudas con Comte sobre este particular véanse las precisiones de Kent (1987, p. 114).
} 
fundaba su comprensión más honda de la historia de las ciencias en las potencialidades de la metodéutica lógica. Reconocer esto constituye una vía fecunda para examinar la preeminencia de los estudios históricos especiales de la ciencia (pero también de la tecnología) en el desarrollo de la lógica peirceana íntegra.

En este mismo sentido se explican el puesto y la función de la memoria 33, "Sobre la lógica objetiva". Peirce indica que con ella fijaría la "clave" para hallar las clases de categorías buscadas en las memorias 29 a 32 a través de un examen de "la lógica de las ideas en tanto que causas agentes físicas" y discusiones del materialismo absoluto, el idealismo absoluto y la lógica objetiva hegelianas, y la naturaleza orgánica de la mente como agente causal (Peirce 2007, p. 144).

V) Memorias 34 a 36. Se ocuparían respectivamente de la uniformidad de la naturaleza, la Metafísica, y la realidad y la naturaleza del tiempo y el espacio. Peirce las concebía como "de la naturaleza de elucidaciones de metodéutica sólida, aplicándola en la práctica a la solución de ciertas cuestiones que, aunque no pertenecen a la lógica, son de especial interés en la discusión de la lógica" (Peirce 2007, p. 144).

\section{Conclusión}

Peirce deseaba concretar el proyecto del LS para difundir los resultados de sus investigaciones personales en lógica. En un plano más abarcador, decididamente "pragmaticista", lo animaba la esperanza de contar entre sus eventuales lectores a varios lo bastante avisados para reconocer que, en última instancia, LS se ofrecía como un estímulo para cultivar el estudio científico de la lógica en todas sus variedades, pero destacadamente entendida como un auxiliar metodéutico, y por consiguiente verían la justificación del requisito básico que les imponía Peirce para semejante tarea: un análisis extensivo y minucioso del origen y el desarrollo de las ciencias, en coordinación con el de los tipos de razonamiento y las metodologías aplicadas por los científicos a lo largo de la historia. En el fondo, pues, la meta de nuestro filósofo no era tanto resolver problemas (lógicos, científicos, filosóficos, históricos) como inspirar a otros el deseo de investigarlos comunitariamente para conseguir, en el largo plazo, su solución.

Peirce tenía una convicción tan profunda de la solidez y el valor de sus propias investigaciones para impulsar aquella empresa compartida, que desahogó en la sección 9 - "Base de mi petición"— su interpretación del sentido infundido en la base 2 de la convocatoria 
emitida por la Institución Carnegie, referente a que la suma concedida estaría invirtiéndose en "descubrir al hombre excepcional en cada campo de estudio", permitiendo al vencedor "hacer el trabajo para el que [...] parece especialmente diseñado" (Peirce 2007, p. 161). No sorprenderá saber, me parece, que aquella interpretación fue literal; la citaré con una supresión y un ligero ajuste, llevado por el deseo de hacerla valer como el colofón ideal de las fracciones medulares en estas páginas: "Soy franco al decir que la idea que esa frase encarna me ha impresionado durante mucho tiempo [...], [y] si es así, el trabajo para el que parece que he sido diseñado es el de desarrollar las verdades de la lógica" (Peirce 2007, p. 162).

\section{BIBLIOGRAFÍA}

Anderson, D.R., 1995, Strands of System. The Philosophy of Charles Peirce, Purdue University Press, West Lafayette.

Fisch, M.H., 1986, Peirce, Semeiotic, and Pragmatism, eds. K.L. Ketner y C.J.W. Kloesel, Indiana University Press, Bloomington.

Hausman, C.R., 1993, Charles S. Peirce's Evolutionary Philosophy, Cambridge University Press, Cambridge.

Kent, B., 1987, Charles S. Peirce. Logic and the Classification of the Sciences, McGill University Press/Queen's University Press, Kingston/ Montreal.

Misak, C., 2004, Truth and the End of Inquiry. A Peircean Account of Truth, Clarendon Press, Oxford.

Nubiola, J., 2005, "The Classification of the Sciences and Cross-disciplinarity", Transactions of the Charles S. Peirce Society, vol. 41, no. 2, pp. 271-282.

Peirce, C.S., 2008, El pragmatismo, ed. y trad. Sara Barrena, Encuentro, Madrid (Opuscula Philosophica, 34).

, 2007, La lógica considerada como semiótica. El índice del pensamiento peirceano, introd., trad. y notas Sara Barrena, Biblioteca Nueva, Madrid (Clásicos del Pensamiento, 41).

- 1992, Reasoning and the Logic of Things: the Cambridge Conferences Lectures of 1898, ed. Kenneth L. Ketner, Harvard University Press, Cambridge, Mass.

- [CP], 1931-1958, Collected Papers, eds. Charles Hartshorne, Paul Weiss y Arthur W. Burks, vol. 5 "Pragmatism and Pragmaticism" y vol. 8 "Reviews, Correspondence, and Bibliography", Harvard University Press, Cambridge, Mass.

Pietarinen, A.-V., 2006, "Interdisciplinarity and Peirce's Classification of the Sciences: A Centennial Reassessment", Perspectives on Science, vol. 14, no. 2, pp. 127-152. 
Ransdell, J., 1998a, "The Significance of Peirce's Application to the Carnegie Institution": <http://www.cspeirce.com/menu/library/bycsp/175/ intro/175intro.htm $>$ [última consulta: 22/05/2009].

—_ 1998b, "Charles S. Peirce. Logic, Considered as Semeiotic. An Overview of Charles Peirce's Philosophical Logic, Constructed from Manuscript L75", version 1: < http://www.cspeirce.com/menu/library/bycsp/ 175/ver1/175vl-01.htm> [última consulta: 22/05/2009].

Robin, R.S., 1967, Annotated Catalogue of the Papers of Charles S. Peirce, The University of Massachusetts Press: <http://www.iupui.edu/ peirce/ robin/robin.htm $>$ [última consulta: 14/04/2009].

Wiener, P. (comp.), 1958, Values in a Universe of Chance. Selected Writings of Charles S. Peirce (1839-1914), Stanford University Press, Stanford.

Recibido el 1 de diciembre de 2009; aceptado el 18 de agosto de 2010. 